оцифрованных астронегативов, выполнена обработка спутников Сатурна (S2-S9), а так же планет Урана, Нептуна и их спутников U1-U4, N1. В качестве опорной системы выбрана система каталога TYCHO2. Внутренняя точность определений положений составила $\pm 0.09- \pm 0.25$ arcsec. В настоящее время выполняются работы по обработке рядов фотографических наблюдений Нептуна, Урана и их спутников, полученных в ГАО за этот же период.

Ключевые слова: каталоги, тела Солнечной системы, Сатурн, Уран, Нептун.

O. Yizhakevych, junior researcher, V. Andruk, researcher,

L. Pakuliak, Ph. D., MAO NAS of Ukraine;

V. Lukianchuk, magister,

Taras Shevchenko National University of Kyiv, Kyiv

\title{
PHOTOGRAPHIC OBSERVATIONS OF MAJOR PLANETS AND THEIR MOONS IN MAO NAS OF UKRAINE DURING 1961-1990
}

We present the results of digitizing and processing of archival observations to obtain the astrometric positions and stellar magnitudes of major planets and their satellites. The work has been done within the framework of the national project "Ukrainian Virtual Observatory" on the basis of photographic observations carried out in MAO NASU. The processing of digital images and the astrometric reduction of data was made in the software package created and developed in MAO for the reduction astrometric negatives. The catalogue includes data of Saturn's moons (S2-S9), obtained using 4 telescopes in 1961-1990. The stellar catalogue TYCHO2 was used as the reference. The internal positional accuracy is $\pm 0.09- \pm 0.25$ arcsec. The same procedure is now applying for the processing of photographic observations of Neptune, Uranus, and their moons, obtained in MAO during the same period.

Key words: catalogues, Solar System bodies, Saturn, Uranus, Neptune.

Удк 524.7

С. Парновський, д-р фіз.-мат. наук, Астрономічна обсерваторія Київського національного університету імені Тараса Шевченка, Київ

\section{ВИЗНАЧЕННЯ ПОЧАТКОВОЇ ФУНКЦІЇ СВІТНОСТІ ГАЛАКТИК З АКТИВНИМ ЗОРЕУТВОРЕННЯМ}

Показано, як визначити початкову функцію світності, що описує розподіл світності галактик при нульовому віці спалаху, на основі поточної функції світності вибірки галактик з активним зореутворенням.

Функція світності (ФС), яка описує розподіл світності галактик, є важливою статистичною характеристикою населення галактик $[1,5]$. Для галактик з активним зореутворенням, світність яких у лінії випромінювання На або в ультрафріолетовому континуумі сильно змінюється у проміжку часу близько декількох мільйонів років, треба розрізняти розподіл початкових світностей галактик та розподіл світностей галактик у вибірці, що досліджується. У роботі [3] введено поняття ФС для початкових світностей $L_{0}$, яку позначимо $n_{1}\left(L_{0}\right)$ та ФС для вибірки, яку позначаємо $n(L)$. У роботі [3] знайдено залежність між цими двома ФС, як у загальному випадку, так і в випадку закону еволюції світності галактик $L$, встановленому в роботі [4] на основі дослідження приблизно 800 компактних яскравих галактик з активним зореутворенням. Закон має вигляд

$$
L(T)=L_{0} \times f(T), \quad f(T)= \begin{cases}1 & T \leq T_{0} \\ \exp \left(-p\left(T-T_{0}\right)\right) & T>T_{0}\end{cases}
$$

де $T$ - проміжок часу після спалаху зореутворення. У роботі [3] було встановлено, що $T_{0}=3.2$ млн років, і значення

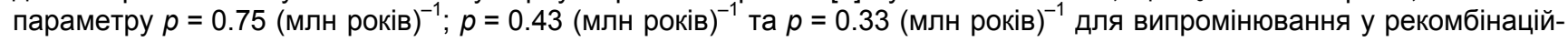
ній лінії Ha, FUV та NUV континуумі, відповідно. Залежність записується у вигляді

$$
n(L)=C\left(n_{1}(L)+q L^{1 / 2} \int_{L}^{\infty} x^{-3 / 2} n_{1}(x) d x\right) .
$$

Параметр $q=\left(p T_{0}\right)^{-1} \in$ фіксованим, параметр $C$ забезпечує потрібне нормування. Якщо обидві функції $n_{1}\left(L_{0}\right)$ та $n(L)$ нормуються однаково, то за результатами роботи [3] можна отримати $C=(1+2 q / 3)^{-1}$. За допомогою (2) у [3] отримано розподіл $n(L)$ за певними розподілами $n_{1}\left(L_{0}\right)$.

У статті розглянуто питання отримання початкової ФС $n_{1}\left(L_{0}\right)$ за відомим розподілом $n(L)$, тобто розв'язку інтегрального рівняння (2). При всій важливості отримання початкової ФС, це питання є математичним і в певній ступені технічним, тому воно розглядається окремо.

Рівняння (2) стосується певного узагальнення лінійних інтегральних рівнянь Вольтерри 2-го роду, але його ядро залежить тільки від $x$, що дає можливість отримати розв'язок. Для цього множимо (2) на $L^{-1 / 2}$ і беремо похідну. Отримуємо диференційне рівняння на $n_{1}$, яке розв'язується підстановкою $n_{1}(L)=L^{q+1 / 2} z(L)$. Пропустимо деталі розрахунку і наведемо розв'язок, який має вигляд

$$
n_{1}\left(L_{0}\right)=\left(1+\frac{2 q}{3}\right)\left(n\left(L_{0}\right)-q L_{0}^{q+1 / 2} \int_{L_{0}}^{\infty} n(x) x^{-q-3 / 2} d x\right) .
$$


Його можна перевірити, якщо підставити у (2). За допомогою (3) можна отримати початкову ФС для певних поточних ФС, зокрема для лог-нормальної ФС, що добре описує спостережні ФС та містить два параметри $а$ та $\tilde{L}$ :

$$
\begin{gathered}
n(L)=\left(\frac{a}{\pi}\right)^{1 / 2} \exp \left(-\frac{1}{4 a}\right) \tilde{L}^{-1} \exp \left(-a \ln ^{2}(L / \tilde{L})\right)=\left(\frac{a}{\pi}\right)^{1 / 2} \exp \left(-\frac{1}{4 a}\right) \tilde{L}^{-1}\left(\frac{L}{\tilde{L}}\right)^{-a \ln (L / \tilde{L})} . \\
n_{1}\left(L_{0}\right)=\left(1+\frac{2 q}{3}\right)\left[\left(\frac{a}{\pi}\right)^{1 / 2} \exp \left(-\frac{1}{4 a}\right) \tilde{L}^{-1} \exp \left(-a \ln ^{2}\left(L_{0} / \tilde{L}\right)\right)-\right.
\end{gathered}
$$

Для неї

$$
\left.-\frac{q}{2} \exp \left(\frac{(q+1 / 2)^{2}-1}{4 a}\right)\left(\frac{L_{0}}{\tilde{L}}\right)^{q+1 / 2} \tilde{L}^{-1} \operatorname{erf}\left(\ln \frac{L_{0}}{\tilde{L}} \sqrt{a}+\frac{q+1 / 2}{2 \sqrt{a}}\right)\right]^{\prime}
$$

де erf - так звана фрункція помилок.

Таким чином, ми отримали формулу (3) для визначення початкової ФС і застосували її до лог-нормальної поточної ФС. Зазначимо, що є стаття [2], в якій також розглядається початкова ФС вибірки галактик шляхом розрахунку їх вихідних світностей за фоомулою (1). Але це початкові ФС зовсім різних вибірок.

Спостережною основою обох досліджень $є$ розподіл світностей компактних яскравих галактик з активним зореутворенням, описаних у $[1,4,5]$. Вони задовольняють певні обмеження на тип, потік, світність у деяких емісійних лініях, тощо. За цими критеріями галактики увійшли в вибірку, яка налічує приблизно 800 галактик. У роботі [2] знайдено розподіл початкових світностей тих самих галактик. Натомість початкова ФС, що обчислена в цій роботі за поточною ФС, $є$ ФС для більшої вибірки, в яку входять компактні яскраві галактики з активним зореутворенням, які на момент останнього спалаху зореутворення, що має вік менш ніж 6 мільйонів років, задовольняли критеріям входження у вибірку. Через еволюцію світностей за законом (1) деякі галактики стали недостатньо світними для входження у вибірку, що досліджується і в якісь момент у минулому вже перестали потрапляти у вибірку. Але їх внесок у початкову $\Phi С n_{1}\left(L_{0}\right)$ залишився. Вона, таким чином, містить галактики, які не входять до вибірки з робіт [2, 4]. Тому не має сенсу порівнювати початкові ФС з цієї роботи, наприклад розподіл (5) з параметрами, отриманими для ФС (4) для вибірки приблизно 800 компактних яскравих галактик з активним зореутворенням, 3 початковою ФС з роботи [2], оскільки вони належать до різних вибірок. Початкова ФС з цієї роботи є вищою для слабких світностей та нижчою для високих світностей порівняно з ФС з роботи [2].

Список використаних джерел

1. Parnovsky S. Multi-wave luminosity functions of starburst galaxies / S. Parnovsky, I. Izotova (in ukr.: С. Парновський. Мультихвильові функції світності галактик з активним зоре утворенням / С. Парновський, І. Ізотова) // Bull. Kyiv National Taras Shevchenko University. Astronomy, 2015. - Bип. (1)52. - C. 15-23.

2. Parnovsky S. Initial luminosity functions of straburst galaxies / S. Parnovsky, I. Izotova (in ukr.: Парновський С. Початкові функції світності галактик з активним зореутворенням / С. Парновський, І. Ізотова) // Bull. Kyiv National Taras Shevchenko University. Astronomy, 2016. - Bип. 54. - C. 10-14.

3. Parnovsky S. L. Impact of the short-term luminosity evolution on luminosity function of star-forming galaxies / S. L. Parnovsky // Astrophysics and Space Sci., 2015. - Vol. 360, article id. 4. -6 p.

4. Parnovsky S. L. Ha and UV luminosities and star formation rates of large sample of luminous compact galaxies / S. L. Parnovsky, I. Yu. Izotova, Y. I. Izotov // Astrophysics and Space Sci., 2013. - N 343. - P. 361-376.

5. Parnovsky S. L. Luminosity function of luminous compact star-forming galaxies / S. L. Parnovsky, I. Yu. Izotova // Astrophysics and Space Sci., 2016. - Vol. 361, article id. 111. - 11 p.

Надійшла до редколегї̈ 15.06.16

С. Парновский, д-р физ.-мат. наук,

Астрономическая обсерватория

Киевского национального университета имени Тараса Шевченка, Киев

\section{НАХОЖДЕНИЕ НАЧАЛЬНОЙ ФУНКЦИИ СВЕТИМОСТИ С АКТИВНЫМ ЗВЕЗДООБРАЗОВАНИЕМ}

Показано, как определить начальную функцию светимости, которая описывает распределение светимостей галактик при нулевом возрасте вспышки звездообразования, зная текущую функцию светимости выборки галактик с активным звездообразованием.

Parnovsky S., Dr. Sci.

Astronomical observatory

of the Taras Shevchenko National University of Kyiv, Kyiv

\section{HOW TO FIND AN INITIAL LUMINOSITY FUNCTIONS OF STARBURST GALAXIES}

We show how to find the initial luminosity function (LF) which appear the distributions of galaxy luminosities at zero starburst age $L_{0}$ from the current LF of the sample of the starburst galaxies. We solve the corresponding Integral equation and get the formula for initial $L F n_{1}\left(L_{0}\right)$ obtained from the $L F n(L)$ of the sample. In particular we consider the case of $n(L)$ being the log-normal function.

УДК $52.14+520.823+524.352$

В. Клещонок, канд. фіз.-мат. наук, І. Лук'яник, канд. фіз.-мат. наук, Київський національний університет імені Тараса Шевченка, Київ

\section{WЕВ-ОРІЄНТОВАНИЙ ІНТЕРФЕЙС ВІДДАЛЕНОГО ДОСТУПУ ДО КИЇВСЬКОГО ІНТЕРНЕТ-ТЕЛЕСКОПА}

Описано часткову модифікацію Київського інтернет-телескопа. Наведено склад телескопа, програмного забезпечення та особливості його роботи. Розлянуто методи роботи з телескопом за допомогою віддаленого доступу.

Ключові слова: Інтернет-телескоп, віддалений доступ. 